\title{
Comparing selected fire regime condition class (FRCC) and LANDFIRE vegetation model results with tree-ring data
}

\author{
Tyson L. Swetnam ${ }^{\mathrm{A}}$ and Peter M. Brown ${ }^{\mathrm{B}, \mathrm{C}}$ \\ A School of Natural Resources and the Environment, The University of Arizona, \\ Tucson, AZ 85721, USA. \\ ${ }^{B}$ Rocky Mountain Tree Ring Research, 2901 Moore Lane, Fort Collins, \\ CO 80526, USA. \\ CCorresponding author. Email: pmb@rmtrr.org
}

\begin{abstract}
Fire Regime Condition Class (FRCC) has been developed as a nationally consistent interagency method in the US to assess degree of departure between historical and current fire regimes and vegetation structural conditions across differing vegetation types. Historical and existing vegetation map data also are being developed for the nationwide LANDFIRE project to aid in FRCC assessments. Here, we compare selected FRCC and LANDFIRE vegetation characteristics derived from simulation modeling with similar characteristics reconstructed from tree-ring data collected from 11 forested sites in Utah. Reconstructed reference conditions based on trees present in 1880 compared with reference conditions modeled by the Vegetation Dynamics Development Tool for individual Biophysical Settings (BpS) used in FRCC and LANDFIRE assessments showed significance relationships for ponderosa pine, aspen, and mixed-conifer BpS but not for spruce-fir, piñon-juniper, or lodgepole pine BpS. LANDFIRE map data were found to be $\sim 58 \%$ accurate for $\mathrm{BpS}$ and $\sim 60 \%$ accurate for existing vegetation types. Results suggest that limited sampling of age-to-size relationships by different species may be needed to help refine reference condition definitions used in FRCC assessments, and that more empirical data are needed to better parameterize FRCC vegetation models in especially low-frequency fire types.
\end{abstract}

Additional keywords: reference conditions, successional classes, Vegetation Dynamics Development Tool (VDDT).

\section{Introduction}

Altered fire regimes and associated changes in vegetation structure, composition, and fuels pose risks to biodiversity, sustainable ecosystems, and economic and community interests across the United States (USDA/USDI 2000). However, the magnitude of these risks varies between ecosystems as a result of differences in their fire and vegetation histories, successional, compositional, and structural dynamics, and the influence of invasive species (Morgan et al. 2001; Schoennagel et al. 2004). Fire exclusion over the 20th century has not affected all ecosystems uniformly, and accurate characterization of historical fire regimes and recent vegetation changes is critical to inform management decisions about the need for fuel treatments or ecological restoration across differing plant communities.

Use of historical fire regimes and vegetation conditions to inform fire and fuel management decisions in the US has been refined into the Fire Regime Condition Class (FRCC) concept (Hann and Bunnell 2001; Schmidt et al. 2002; Hann and Strohm 2003; Hann et al. 2003; Shlisky and Hann 2003). FRCC is an index that compares current with historical fire regimes and vegetation composition and structure to assess degree of departure on a scale from one (least departed) to three (most departed). FRCC is based on an assumption that historical processes and patterns (those present before widespread Euro-American settlement in the mid- to late-1800s) represent longer-term sustainable ecosystem conditions, and that greater departure in current conditions represents a greater risk for uncharacteristic fire behavior and associated ecosystem impacts. Initial coarse-level (1-km² resolution) FRCC maps described the degree of departure at a national scale (Schmidt et al. 2002). After this initial effort, a set of standard guidebook methods was developed to assess FRCC at landscape to stand scales for local management and planning needs (at time of writing, FRCC Guidebook v1.3; Hann et al. 2004). FRCC maps of 30- $\mathrm{m}^{2}$ resolution are also being developed as part the LANDFIRE project, an effort to provide consistent vegetation, fuels, and fire regime data for the entire US (Rollins and Frame 2006; www.landfire.gov, accessed 19 October 2007). FRCC is now a key variable for defining wildfire risk to ecosystems as a result of its explicit incorporation into the Healthy Forests Restoration Act of 2003 (HFRA 2003). FRCC represents a significant advance in the integration of fire and forest histories and landscape and vegetation ecology to provide an ecologically based method for setting fire-management priorities and objectives across the US (Shlisky and Hann 2003).

Definition of departure indices in FRCC assessments begins with simulation modeling of historical vegetation composition and structure using the Vegetation Dynamics Development Tool (VDDT; Beukema and Kurz 2003). VDDT is used to develop non-spatially defined reference conditions within Biophysical Settings (BpS; formerly referred to as Potential Natural Vegetation Groups (PNVG); Küchler 1964; NRCS 2003). For LANDFIRE, BpS are derived from Nature Serve's ecological 
classification system (Comers et al. 2003) and are not directly comparable with those used in FRCC assessments. However, both systems use $\mathrm{BpS}$ in a similar manner to represent the vegetation communities that would likely exist under given environmental conditions (climate, soils, and landscape physiography) and historical disturbance regimes. BpS in LANDFIRE are assigned to specific locations in their nationwide mapping efforts, whereas BpS in FRCC assessments are non-spatial and assigned based on individual user needs for specific projects or management requirements. Reference conditions are the proportions of vegetation successional stages (community structure and composition) as affected by varying fire frequencies, severities, and successional pathways within each BpS (Hann et al. 2004).

FRCC and LANDFIRE vegetation models (also known as Vegetation Dynamics Models) were defined during regional professional workshops conducted between 2002 and 2009 (2005-09 for LANDFIRE). VDDT model inputs for individual $\mathrm{BpS}$ are based on historical fire regime characteristics (frequency and severity) and vegetation data derived from published and unpublished studies and expert opinion developed both at the regional workshops and through subsequent peer reviews (Hann et al. 2004). The amount and quality of available historical data for each BpS vary, which can affect the quality and accuracy of the resulting modeled reference conditions. In an FRCC assessment, a field evaluation is conducted of existing vegetation structure, which, in forests, is based on cover type, density of tree stands, tree size, and current successional status. Successional status is determined by visually estimating stand composition, tree density, and average tree age, the latter of which is based on tree diameters. Proportions of current successional classes in a project or management area are estimated during the field assessment and then compared with the proportions of reference conditions derived from VDDT model output. The FRCC departure index ( 1 to 3 ) is assigned based at least partially on differences in proportions of successional classes present in the current forest relative to modeled reference conditions in the historical forest.

There is a need to test the process of development of reference conditions by comparing VDDT model output with known fire and vegetation histories. This comparison is critical for assessing consistency and accuracy in the modeling process. Here, we compare VDDT-modeled reference conditions with tree-ringbased reconstructions of reference conditions from 11 forested sites in Utah and eastern Nevada (tree-ring data reported in Heyerdahl et al. 2005, and Brown et al. 2008a). The tree-ring reconstructions span transects aligned along elevation gradients that include multiple forest types. We ask the following questions with this comparison: (1) do FRCC methods of evaluating stand structure based on diameter estimates accurately represent ages of forest vegetation and is there variation based on species and site? (2) Do FRCC and LANDFIRE BpS models adequately capture the range of variation in proportions of reference conditions reconstructed by the tree-ring data? (3) Do LANDFIRE mapped data layers for BpS and Existing Vegetation Types (EVT) match the tree-ring plot data? (4) Can further empirical fire history and tree recruitment data be used to strengthen FRCC evaluation and reference condition modeling outputs? We consider this study to be only an initial test of FRCC and LANDFIRE vegetation modeling methods, but one that may provide an example for future testing needs.

\section{Methods}

Study area

Tree-ring sites used for this study extend from the Colorado Plateau of southern Utah, west to the Wah Wah Mountains in the eastern Great Basin of western Utah, and north to the Uinta and Bear River Mountains in northern Utah (Fig. 1, Table 1; Heyerdahl et al. 2005; Brown et al. 2008a). The region is a complex of valleys, mesas, canyons, plateaus, and mountains that range in elevation from $\sim 900$ to $>3600 \mathrm{~m}$. Forest types vary generally across elevation gradients. Piñon (Pinus edulis (PIED; four-letter codes are used in tables) and P. monophylla (PIMO)) and juniper (Juniperus scopulorum (JUSC) and J. osteosperma (JUOS)) savannas and woodlands occur at the lowest forest margins above desert shrublands or grasslands. Ponderosa pine (Pinus ponderosa (PIPO)) forests occur in montane zones in pure and mixed stands. Douglas-fir (Pseudotsuga menziesii (PSME)) often occurs in association with ponderosa pine on north-facing aspects and in relatively mesic sites. Mixed-conifer forests occur at intermediate elevations and include combinations of ponderosa pine, Douglas-fir, piñons, junipers, and firs (Abies lasiocarpa (ABLA) or A. concolor (ABCO)). Mixed-conifer forests also often occur in association with aspen (Populus tremuloides (POTR)). Aspen forms large (>100 ha) pure stands throughout the upper montane and lower subalpine zones across the study area except in the Great Basin. Lodgepole pine (Pinus contorta (PICO)) often forms pure stands at mid-elevations (1900 to $2800 \mathrm{~m}$ ) or occurs in the mixed-conifer zone in northern Utah. Subalpine forests dominated by Engelmann spruce (Picea engelmannii (PIEN)) and firs occur at upper elevations ( 2350 to $3500 \mathrm{~m}$ ). At the highest forested elevations (generally above $3000 \mathrm{~m}$ ), pure Engelmann spruce forests occur in mesic sites whereas bristlecone pine (Pinus longaeva (PILO)) or limber pine (P. flexilis (PIFL)) are typically found in dry or rocky sites.

There was, in general, a gradient in fire frequency across the elevational gradient before fire exclusion that began at all sites in the late 1800s (Heyerdahl et al. 2005; Brown et al. 2008a). Fire occurrence was highest in the middle of the elevation range in ponderosa pine and drier mixed-conifer sites. Fire frequency progressively declined both above and below this middle-elevation zone. At upper elevations, generally moist conditions led to high fuel biomass, both living and dead, in many stands, but fewer years in which fuels were dry enough to ignite and spread. At lower elevations in the piñon-juniper woodlands, fuels were often dry enough to burn because of hotter and dryer fire seasons, but because of lower productivity, there were in general less continuous both aerial and surface fuels and fires were not able to spread. In the middle zone, both fuel amounts and moistures were just right (what has come to informally be called the 'Goldilocks effect'), and able to burn often in wide-spreading fires.

Utah forests underwent a period of intensive grazing and land use beginning in the $1850 \mathrm{~s}$ as a result of Euro-American settlement. Intensive grazing removed understorey species and began alteration of longer-term historical forest dynamics. Logging also affected forest structure in many areas. The tree-ring study found that cessation of historical patterns of fires began in 


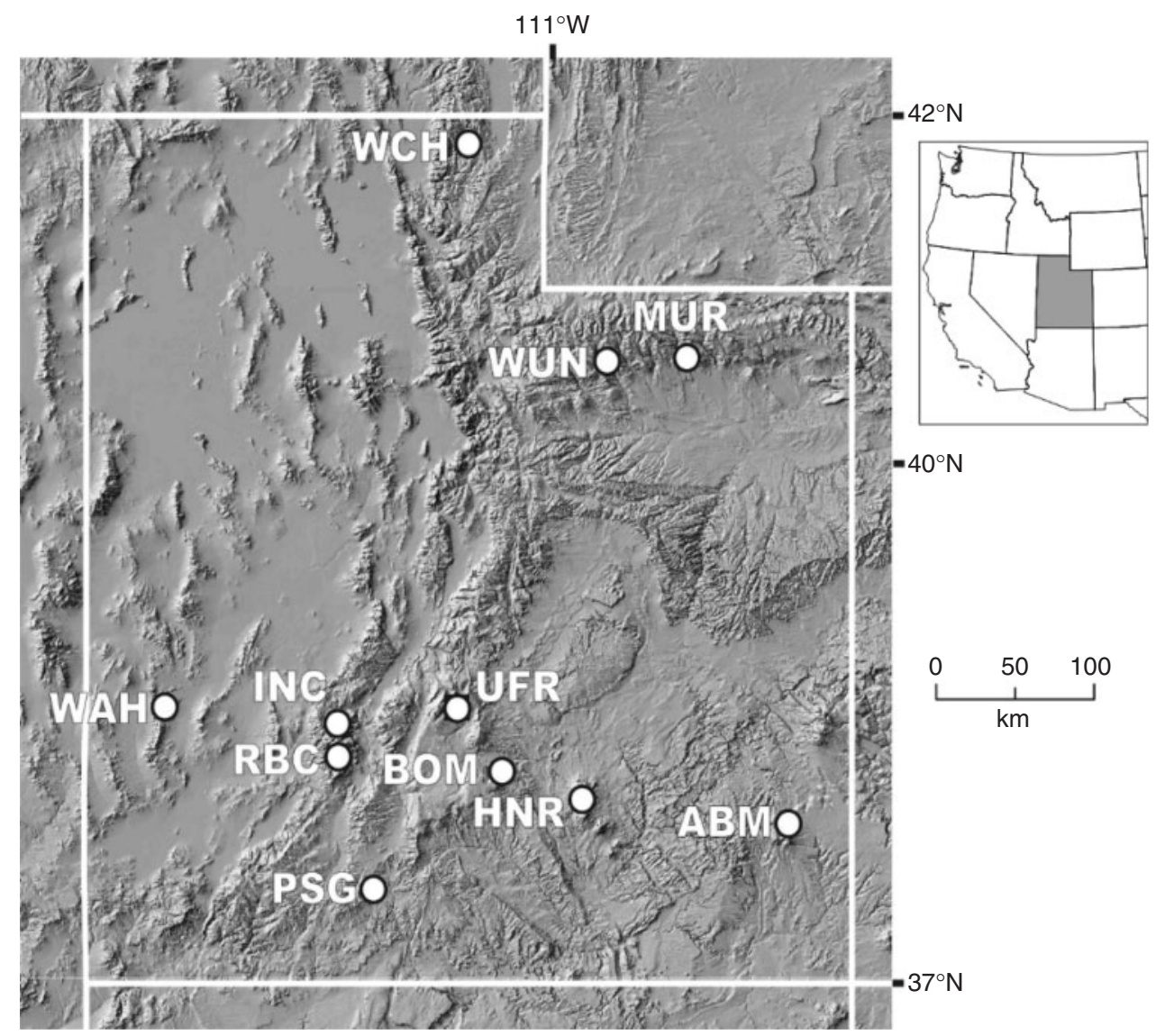

Fig. 1. Locations of tree-ring sites. Three-letter codes correspond to those in Table 1.

Table 1. Tree-ring sites used in the present study arranged from north to south

FRCC (Fire Regime Condition Class) and LANDFIRE BpS (biophysical settings) forest types are listed in Table 4

\begin{tabular}{|c|c|c|c|c|}
\hline Site & $\begin{array}{c}\text { Minimum } \\
\text { elevation }(\mathrm{m})\end{array}$ & $\begin{array}{l}\text { Maximum } \\
\text { elevation }(\mathrm{m})\end{array}$ & $\begin{array}{c}\text { Average } \\
\text { precipitation }(\mathrm{cm})\end{array}$ & FRCC and LANDFIRE BpS \\
\hline Wasatch Mountains (WCH) & 2255 & 2588 & 100 & SPFI, SPDF, CHPI, 10510, 10520, 10500, 10550 \\
\hline Middle Uinta River (MUR) & 2308 & 3250 & 70 & PPIN, SPDF, SPFI, CHPI, 10540, 10510, 10520, 10500, 10550 \\
\hline Wah Wah Mountains (WAH) & 2195 & 2686 & 40 & JUPI, PPIN, SPDF, 10160, 10540, 10500 \\
\hline Upper Fremont River (UFR) & 2800 & 3039 & 80 & SPDF, SPFI, $10510,10520,10500$ \\
\hline Indian Creek (INC) & 2364 & 2518 & 65 & PPIN, SPDF, 10540, 10500 \\
\hline Beaver Creek (RBC) & 2358 & 3077 & 90 & PPIN, SPDF, SPFI, 10540, 10510, 10520, 10500 \\
\hline Boulder Mountain (BOM) & 2405 & 3377 & 80 & JUPI, PPIN, SPDF, SPFI, 10160, 10540, 10510, 10520, 10500 \\
\hline Henry Mountains (HNR) & 2407 & 3138 & 60 & JUPI, PPIN, SPDF, 10160, 10540, 10500 \\
\hline Abajo Mountains (ABM) & 2557 & 3231 & 85 & JUPI, PPIN, SPDF, SPFI, 10160, 10510, 10520, 10500 \\
\hline Paunsaugunt Plateau (PSG) & 2309 & 2736 & 45 & JUPI, PPIN, SPDF, SPFI, 10160, 10540, 10510, 10520, 10500 \\
\hline
\end{tabular}

the 1860 s to 1890 s depending on location (Brown et al. 2008a), similar to patterns seen in forests throughout the western US. Initial reduction in fire frequency was likely the result of grazing that removed grass and herbaceous fuels, followed later by direct fire suppression in the 20th to 21 st centuries.
Tree-ring data

The tree-ring study used a systematic sampling design to characterize stand and age structure and fire regimes across forest gradients in each site (Table 1; Heyerdahl et al. 2005; Brown et al. 2008a). Similar methods have been used in multiple studies 
around the western US and are described in more detail in Heyerdahl et al. (2005, 2006), Brown and Wu (2005), Brown (2006), Brown et al. (2008a, 2008b), and Brown and Schoettle (2008). A 500-m grid was established at each site and plots sampled at grid points. Plot centers were located in the field using hand-held global positioning system (GPS) units. An $n$ tree density-adapted sampling method (Jonsson et al. 1992) was used to collect data from the nearest $\sim 30$ remnant (logs, snags, or stumps) or living trees $>20 \mathrm{~cm}$ diameter at breast height (DBH) to each plot center. Maximum plot radius was set at $40 \mathrm{~m}(\sim 0.5 \mathrm{ha})$ and most plots were $\sim<0.2$ ha in size. For each plot tree, species was recorded and an increment core (on living trees) or cross-section (from logs, snags, and stumps) was collected from $\sim 10 \mathrm{~cm}$ height above ground. Sampled cores had to be no more than a field-estimated 10 years from pith to minimize pith offset when assessing pith date. Diameter at sample height (DSH) and DBH were measured on living trees, and DSH was measured or estimated for remnant trees missing bark, sapwood, or heartwood. Distance from plot center and azimuth were measured on all trees for reconstruction of tree basal areas, density, and spatial patterning. To reconstruct surface fire history, crosssections were cut from any fire-scarred trees found within plots. Additional fire-scarred trees also were sampled within $\sim 80 \mathrm{~m}$ of each grid point and between grid points when discovered. GPS coordinates and species of fire-scarred trees outside of plots were recorded.

Standard dendrochronological methods were used to crossdate all samples using locally developed master chronologies (Heyerdahl et al. 2005). Pith dates were estimated on cores that did not intersect pith based on the curvature of the innermost rings sampled. The tree recruitment date is considered to be the date of tree pith at $10-\mathrm{cm}$ height. No corrections were made for time to grow from germination to $10 \mathrm{~cm}$ sample heights because of the widely varying species and environmental conditions at the sites that were collected for the study. Once crossdating of ring series was completed on all samples, dates for any fire scars seen within the ring series were assigned. Any trees that were not able to be dated were not used in subsequent analyses.

\section{FRCC and LANDFIRE vegetation models}

VDDT modeling estimates the relative proportions of nonspatially defined reference conditions that would have occurred under a historical fire regime and an equilibrium (current) climate regime within each BpS (Beukema and Kurz 2003). VDDT input includes average fire frequencies, severities, and other disturbances defined as probabilistic events, and vegetation structural stage development pathways, including changes in species composition and density through a successional sequence. VDDT runs are commonly made for 500 years to allow vegetation conditions to equilibrate over time. VDDT output is proportions of vegetation successional classes - the reference conditions - across a non-spatially referenced landscape at the end of the 500-year model run. Reference conditions for most forest types are summarized into five seral stages that approximate overall developmental characteristics of community age and structure: early-replacement, mid-open, mid-closed, late-open, and late-closed. Each developmental stage represents a successional class defined by average tree age, species composition, structural characteristics, and response to disturbances. LANDFIRE and FRCC assessments use VDDT in a similar manner, but in LANDFIRE, reference condition proportions are then coupled with the spatial model LANDSUM (Keane et al.2002) to map resulting vegetation conditions for each $\mathrm{BpS}$ across actual landscapes at a $30-\mathrm{m}^{2}$ spatial resolution.

FRCC and LANDFIRE developed their own BpS models using two different vegetation classification systems (Küchler 1964 v. Comers et al. 2003). Both systems attempt to describe the same historical vegetation using VDDT; however, their models use different probabilities for disturbance, and have somewhat different species distributions and geographic extents (often based on expert opinion; see http://frcc.gov, accessed 19 October 2007; www.landfire.gov for details).

\section{Comparing tree-ring with FRCC and LANDFIRE data}

We performed three tests to compare the tree-ring data with FRCC and LANDFIRE vegetation models. First, we compiled age and DBH data derived from the tree-ring study to assess whether FRCC methods of visual estimates of tree diameters accurately represent the age of forest vegetation for defining midand late-development classes of reference conditions. FRCC guidebook methods define $>23 \mathrm{~cm} \mathrm{DBH}$ as a visual indicator of a mature tree when conducting field assessments. For this analysis, we assumed that plots with trees averaging $\leq 23 \mathrm{~cm}$ DBH would be considered to be in a mid-development reference condition, and $>23 \mathrm{~cm}$ would be in late-development. We conducted least-squares linear regressions to estimate fitness of tree age to DBH by species and site. As many of the regression models did not meet the statistical requirements of homoscedasticity, normality, and constant variance in model residuals, a logarithmic transformation was applied to the tree ages before regression. Models that had significant $P$ values $(P<0.05)$ were considered to be representative of species growth estimates. We also conducted an analysis of variance (ANOVA) of age and diameter by species and site to both determine the strength of these relationships and how they varied by species and location across the region. All statistical analyses were conducted using the Statistica software (StatSoft Inc. 2008). The tree-ring study sampled a total of $\sim 10000$ remnant and living trees; however, we only used data from the living trees for this part of our assessment. Dead trees (stumps, snags, and logs) often were missing bark, sapwood, or portions of the heartwood that reduced confidence in diameter estimates. The DBH-to-age analysis therefore consisted of 5173 living trees from 13 species from the 11 sites.

Our second test was whether VDDT modeled reference conditions captured the range of variation in reference conditions reconstructed by the tree-ring data as of a date of 1880. Dates of initial Euro-American settlement varied across the study area but all sites showed some Euro-American impact by 1880 , including cessation of spreading fires in almost all of the sites (Brown et al. 2008a). As current vegetation may not be representative of past vegetation type, only species present in 1880 and their corresponding ages were used to assign $\mathrm{BpS}$ and reference condition to each of a total of 273 plots that were sampled from the 11 sites (Heyerdahl et al. 2005; Brown et al. 2008a). Both living and remnant trees were used to estimate the 1880 plot compositions. FRCC and LANDFIRE use key species to 

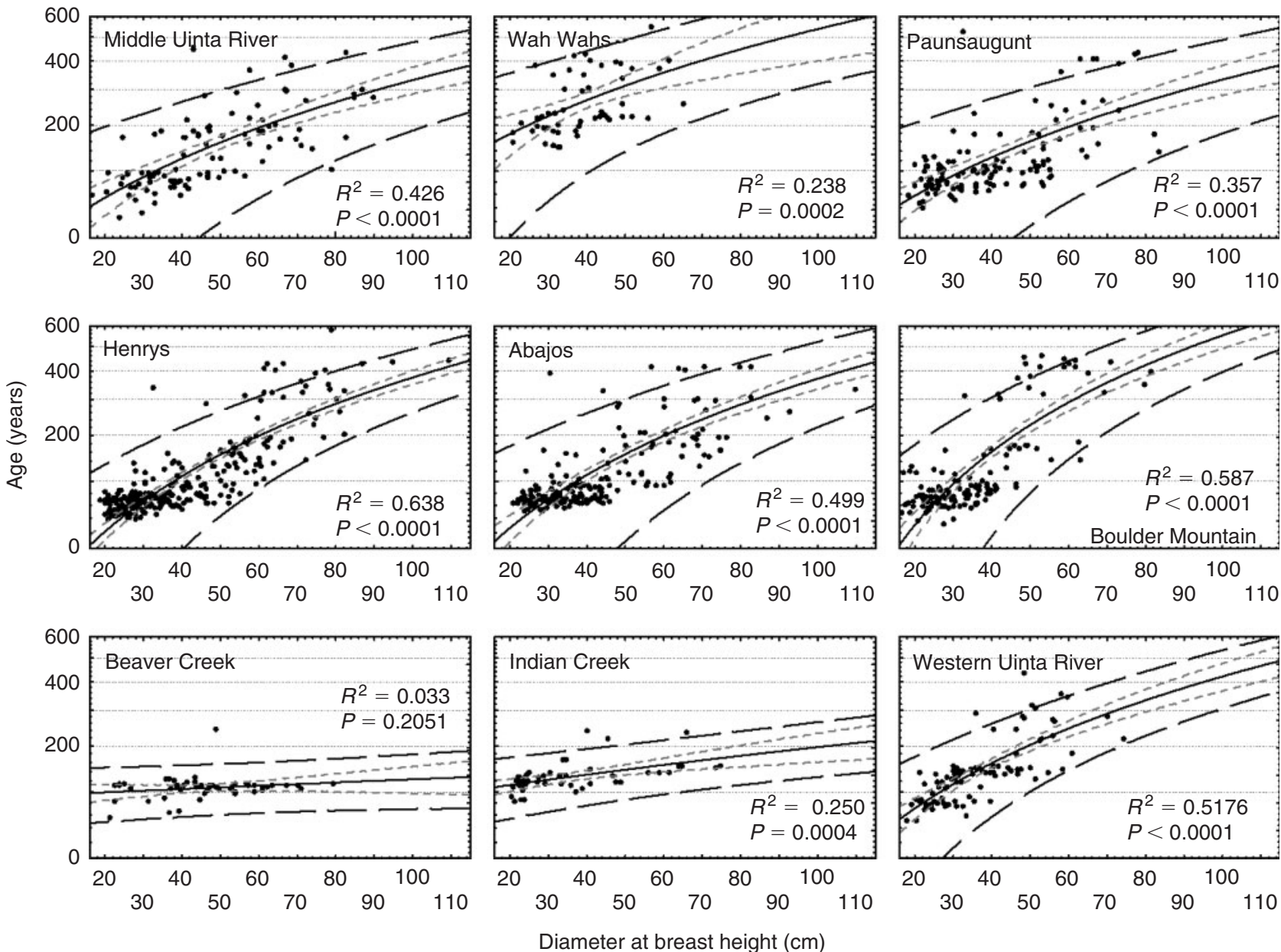

Fig. 2. Diameter at breast height (DBH) and $\log (\mathrm{age})$ regressions for ponderosa pine trees by site, with linear fits (solid lines), $95 \%$ confidence intervals (gray dashed lines), and 95\% prediction intervals (black dashed lines). Overall $R^{2}$ for ponderosa pine trees across all sites was 0.44 .

define vegetation characteristics when conducting an assessment and we used these species as the basis for assigning $\mathrm{BpS}$ and reference condition to each plot.

Historical age class and species composition in 1880 for each plot were compared with FRCC and LANDFIRE reference conditions for selected BpS. FRCC and LANDFIRE BpS descriptions are available on their respective project websites (www.frcc.gov; www.landfire.gov). We did not evaluate the typical five-stage VDDT models because of difficulties in using the tree-ring data to accurately recreate smaller size classes in historical stand densities as a result of probable tree mortality and decay since pre-settlement periods (e.g. Brown and Cook 2006; Brown et al. 2008b). However, we assume that we are able to define with some confidence mid- and late-development stands based on crossdated ages of trees present in each plot in 1880 . The mean age of a $23-\mathrm{cm}-\mathrm{DBH}$ live tree varied by species, and we used the tree-ring results to estimate the upper $95 \%$ confidence interval for predicted tree size to consider whether a stand was late developmental stage in 1880 . We grouped data from open and closed stands together based on age and composition for comparison with succession classes from VDDT output. If any trees in a plot were older than their predicted age-to-size confidence interval, the plot was considered to be in late-development in 1880. If there were no older trees during the historical period, then the plot was considered to have been in mid-development. If there were no trees during the historical period, the plot was considered to have no data and not used in this analysis. Once plots were categorized by $\mathrm{BpS}$ and reference condition, they were compared with FRCC and LANDFIRE $\mathrm{BpS}$ model proportions of mid- and late-development vegetation based on VDDT output. We used a Chi-square test to determine if the observed tree-ring reference condition proportions were significantly different than the expected based on the VDDT output.

Finally, we compared tree-ring plot data with LANDFIRE BpS and EVT map layers produced by the LANDFIRE project. LANDFIRE data are spatially mapped, which provided a unique opportunity to evaluate vegetation models at a high spatial resolution through comparison with the mapped tree-ring data. Plots were first located through their GPS coordinates relative to LANDFIRE map data. The BpS assignments we made for each plot in 1880 were then compared with LANDFIRE BpS map data. We also compiled the living tree composition in each plot and compared that with the LANDFIRE EVT map data. If key 

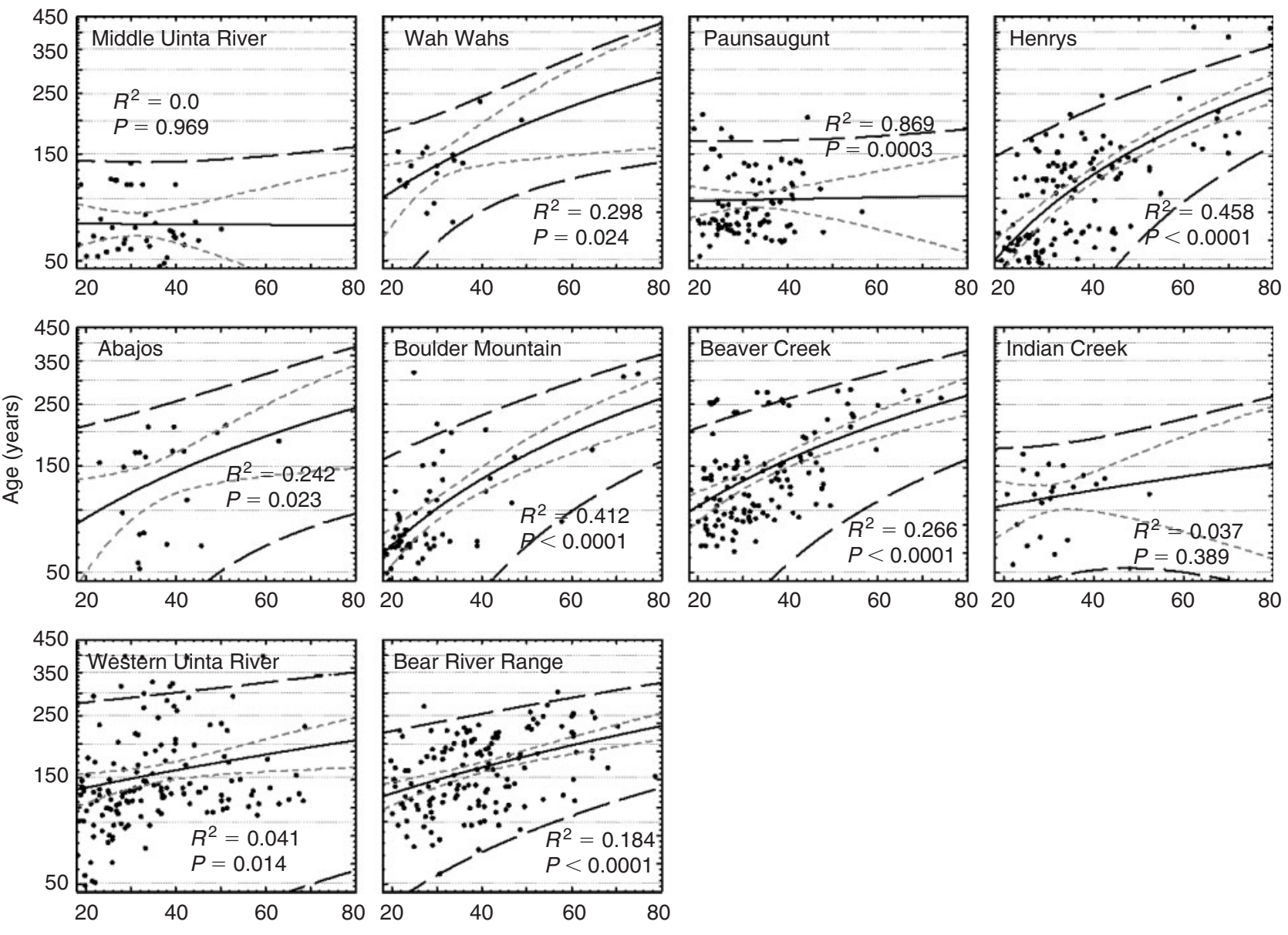

Diameter at breast height $(\mathrm{cm})$

Fig. 3. Diameter at breast height (DBH) and $\log ($ age) regressions for Douglas-fir trees by site, with linear fits (solid lines), $95 \%$ confidence intervals (gray dashed lines), and $95 \%$ prediction intervals (black dashed lines). Overall $R^{2}$ for Douglas-fir trees across all sites was 0.21 .

species were present in the tree-ring data in comparison with the mapped $\mathrm{BpS}$ or EVT, then the grid point was considered to have been accurately mapped in LANDFIRE.

\section{Results}

\section{Age-diameter relationships}

DBH and tree ages exhibited generally broad relationships, both within species and among sites (Figs 2-4; Tables 2, 3). Ponderosa pine was the only species where age and size were strongly correlated using data from all sites $\left(R^{2}=0.438, P<0.001\right)$ and were strongly correlated over most of the individual sites (Table 2). There were outliers for most species by DBH and age; however, their deviance did not significantly change the results. Median tree age was predicted for trees at $23 \mathrm{~cm}$ using an inverse prediction with $95 \%$ confidence interval (Table 3). ANOVA results indicate that species associated with infrequent fire regimes (piñon-juniper, spruce-fir, and bristlecone pine; Heyerdahl et al. 2005) were found to have greater average ages than frequent fire species (especially ponderosa pine and Douglas-fir; Fig. 5). Variance of diameters relative to ages for species that contained a large sample $n$, such as Douglas-fir (PSME), ponderosa pine
(PIPO), and Engelmann spruce (PIEN) was small. There was greater variance found in species that had fewer sampled trees and plots, such as bristlecone pine (PILO), Rocky Mountain juniper (JUSC), one-seed juniper (JUOS), limber pine (PIFL), and single leaf piñon (PIMO), but this result is likely an artifact of the smaller number of trees used in each regression. ANOVA indicated that $\mathrm{DBH}$ and age estimates for all sites were similar with the exception of WAH (Fig. 5). This may be explained by the large presence of fire-infrequent and older species (bristlecone pine, Rocky Mountain juniper, and one-seed juniper) that were sampled in that site.

\section{FRCC and LANDFIRE BpS models}

Median ages of trees $>23 \mathrm{~cm}$ DBH were used to define the proportions of mid- and late-development reference conditions for trees present in plots in 1880 (Table 3). Reference condition proportions reconstructed from the tree-ring data compared favorably with FRCC BpS models for ponderosa pine (PPIN5), mixed-conifer (SPDF), and lodgepole (CHPI) but not for piñon-juniper (JUPI1, JUPI2), south-western mixed-conifer (MCAN) and spruce-fir (SPFI2, SPFI7; Table 4, Fig. 6). Reference condition proportions reconstructed from the tree-ring data 

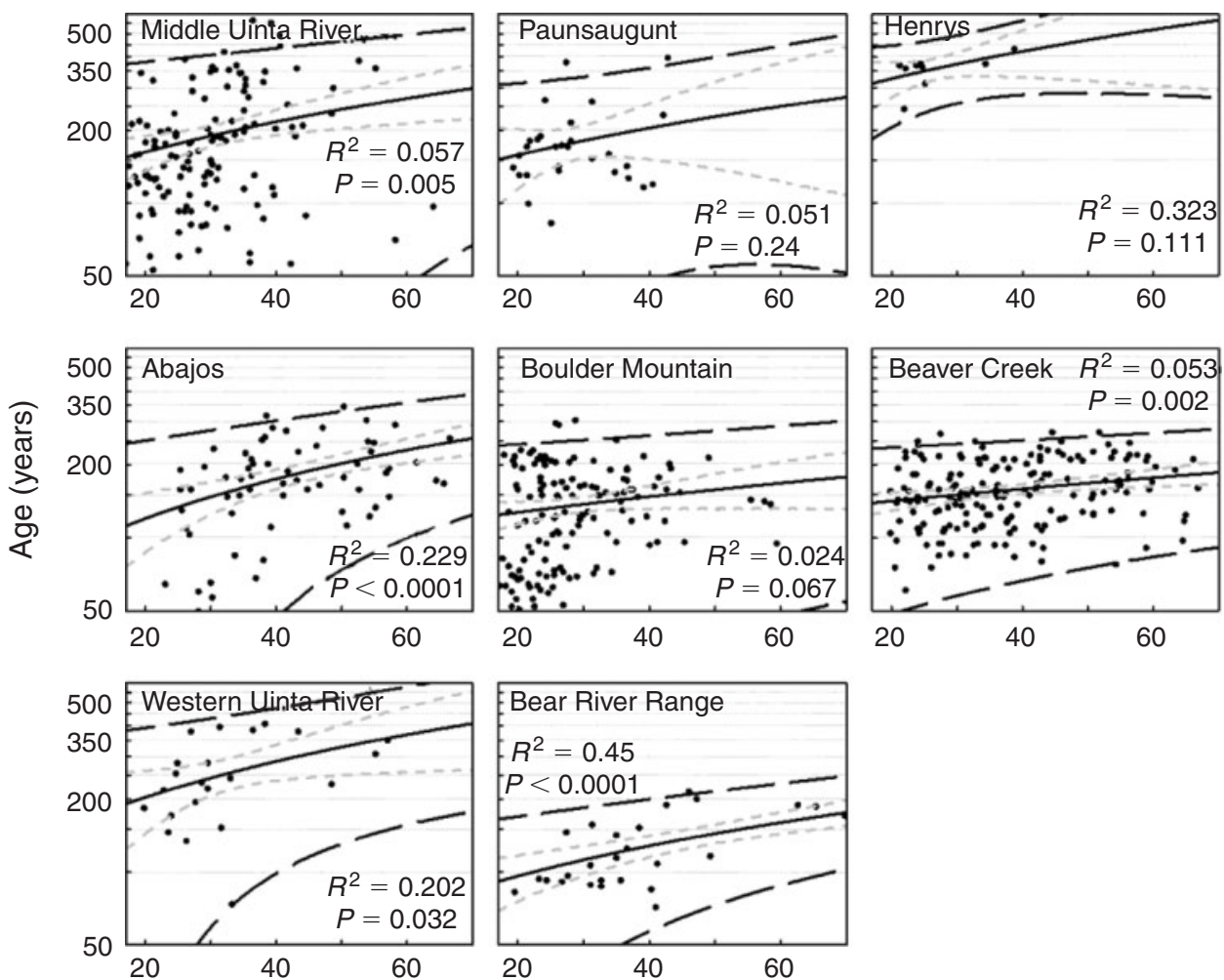

Diameter at breast height $(\mathrm{cm})$

Fig. 4. Diameter at breast height $(\mathrm{DBH})$ and $\log (\mathrm{age})$ regressions for Engelmann spruce trees by site, with linear fits (solid lines), 95\% confidence intervals (gray dashed lines), and 95\% prediction intervals (black dashed lines). Overall $R^{2}$ for Engelmann spruce trees across all sites was 0.06 .

Table 2. Observed two-sided $\boldsymbol{P}$ values for $\mathrm{DBH}$-age regressions for all species at all sites

Bold values represent locations where $P$ values are significant at the $95 \%$ confidence interval $(<0.05)$ based on sample size $(>10$ trees $)$

\begin{tabular}{|c|c|c|c|c|c|c|c|c|c|c|}
\hline \multirow[t]{2}{*}{ Species } & \multicolumn{10}{|c|}{ Site } \\
\hline & WCH & $\mathrm{RBC}$ & $\mathrm{ABM}$ & BOM & HNR & PSG & INC & WUN & MUR & WAH \\
\hline PIPO & & 0.021 & $<0.0001$ & $<0.0001$ & $<0.0001$ & $<0.0001$ & 0.0004 & $<0.0001$ & $<0.0001$ & 0.0002 \\
\hline PSME & $<0.0001$ & $<0.0001$ & 0.0234 & $<0.0001$ & $<0.0001$ & 0.88 & 0.39 & 0.01 & 0.969 & 0.024 \\
\hline PIEN & $<0.0001$ & $<0.0001$ & $<0.0001$ & 0.066 & 0.111 & 0.241 & & 0.03 & 0.005 & \\
\hline ABLA & $<0.0001$ & 0.19 & $<0.0001$ & & 0.147 & & & 0.37 & & \\
\hline POTR & 0.01 & 0.01 & $<0.0001$ & 0.63 & 0.107 & & 0.40 & 0.81 & 0.020 & \\
\hline PICO & $<0.0001$ & & & & $<0.0001$ & 0.0007 & & & & \\
\hline PIFL & 0.28 & & & & $<0.0001$ & 0.090 & 0.28 & & & \\
\hline PIED & & & & $<0.0001$ & $<0.0001$ & 0.025 & & & & \\
\hline PIMO & & & & & & & & & & $<0.0001$ \\
\hline JUSC & & & & 0.152 & & 0.111 & & & & 0.903 \\
\hline JUOS & & & & 0.0003 & & 0.677 & & & 0.797 & 0.0002 \\
\hline PILO & & & & & & & & & & 0.574 \\
\hline
\end{tabular}

compared favorably with LANDFIRE BpS models for Rocky Mountain dry-mesic montane mixed-conifer (10510), aspen and aspen-mixed-conifer low- and high-elevation forests (10110, $10611,10612)$, but not for piñon-juniper (10160), ponderosa pine (10540), Rocky Mountain mesic montane mixed-conifer
(10520), Rocky Mountain subalpine dry-mesic spruce-fir forest and woodland (10550), and Rocky Mountain lodgepole pine (10500; Table 4, Fig. 6). The JUPI1 BpS model (Table 4) was the most different from the tree-ring data, although the JUPI2 model had a similar trend of a larger proportion of late-successional 
stands in comparison with the tree-ring data (Fig. 6). Spruce-fir and lodgepole pine data both showed low correspondence with VDDT model results, including opposite trends of more older than younger stands in the tree-ring data in contrast to the VDDT modeled reference conditions (Fig. 6).

Table 3. Expected median ages of trees $>23 \mathrm{~cm}$ DBH (diameter at breast height) by species, with lower and upper $95 \%$ confidence intervals derived from tree-ring data

$\mathrm{NS}$, age-DBH regression not significant

\begin{tabular}{lclr}
\hline Species & Age (years) at $23 \mathrm{~cm}$ & $R^{2}$ & $P$ value \\
\hline PIPO & $40.9 \pm 3.2$ & 0.438 & $<0.0001$ \\
JUOS & $114.9 \pm 41.9$ & 0.438 & $<0.0001$ \\
PIED & $135.3 \pm 21.9$ & 0.28 & $<0.0001$ \\
PIFL & $66 \pm 11.4$ & 0.271 & $<0.0001$ \\
PIMO & $176.3 \pm 29.8$ & 0.231 & $<0.0001$ \\
PSME & $42.9 \pm 6$ & 0.213 & $<0.0001$ \\
PICO & $54.3 \pm 12.6$ & 0.112 & $<0.0001$ \\
POTR & $104 \pm 9.1$ & 0.095 & $<0.0001$ \\
PIEN & $24.7 \pm 14.7$ & 0.055 & $<0.0001$ \\
JUSC & $\mathrm{NS}$ & 0.05 & 0.0961 \\
ABCO & $14.8 \pm 14.4$ & 0.023 & $<0.0001$ \\
PILO & $\mathrm{NS}$ & 0.012 & 0.6295 \\
ABLA & $50.2 \pm 10.2$ & 0.01 & $<0.0001$ \\
\hline
\end{tabular}

\section{LANDFIRE map data}

LANDFIRE map layers were found to be overall 58\% accurate for $\mathrm{BpS}$ and $60 \%$ accurate for EVT when compared with the tree-ring data for each plot (Table 5). LANDFIRE maps were $38 \%$ accurate for both $\mathrm{BpS}$ and EVT, 28\% accurate for at least one type (17\% EVT accurate and BpS inaccurate, with $11 \%$ $\mathrm{BpS}$ accurate and EVT inaccurate), and 34\% inaccurate. Mixedconifer and spruce-fir types had the highest accuracies by BpS for LANDFIRE with accuracies ranging from 64 to $82 \%$ for BpS and 67 to $79 \%$ for EVT. Piñon-juniper was the least accurately mapped BpS and EVT with 13 and 37\% accuracy respectively.

\section{Discussion}

\section{FRCC and LANDFIRE BpS models}

Current stand conditions are determined through visual estimates of stand structure, including tree diameters, in FRCC assessments (Hann et al. 2004). FRCC assessments are designed to be a relatively rapid method of characterizing current vegetation and fire regime departures from historical conditions. The expense of collecting field data, such as canopy closure, canopy base height, tree density, stand age structure, and fire and stand histories, make field sampling impractical for FRCC assessments. However, based on the limited findings of this study, it appears that FRCC methods may result in inaccurate measures of plant community departure based on visually estimated

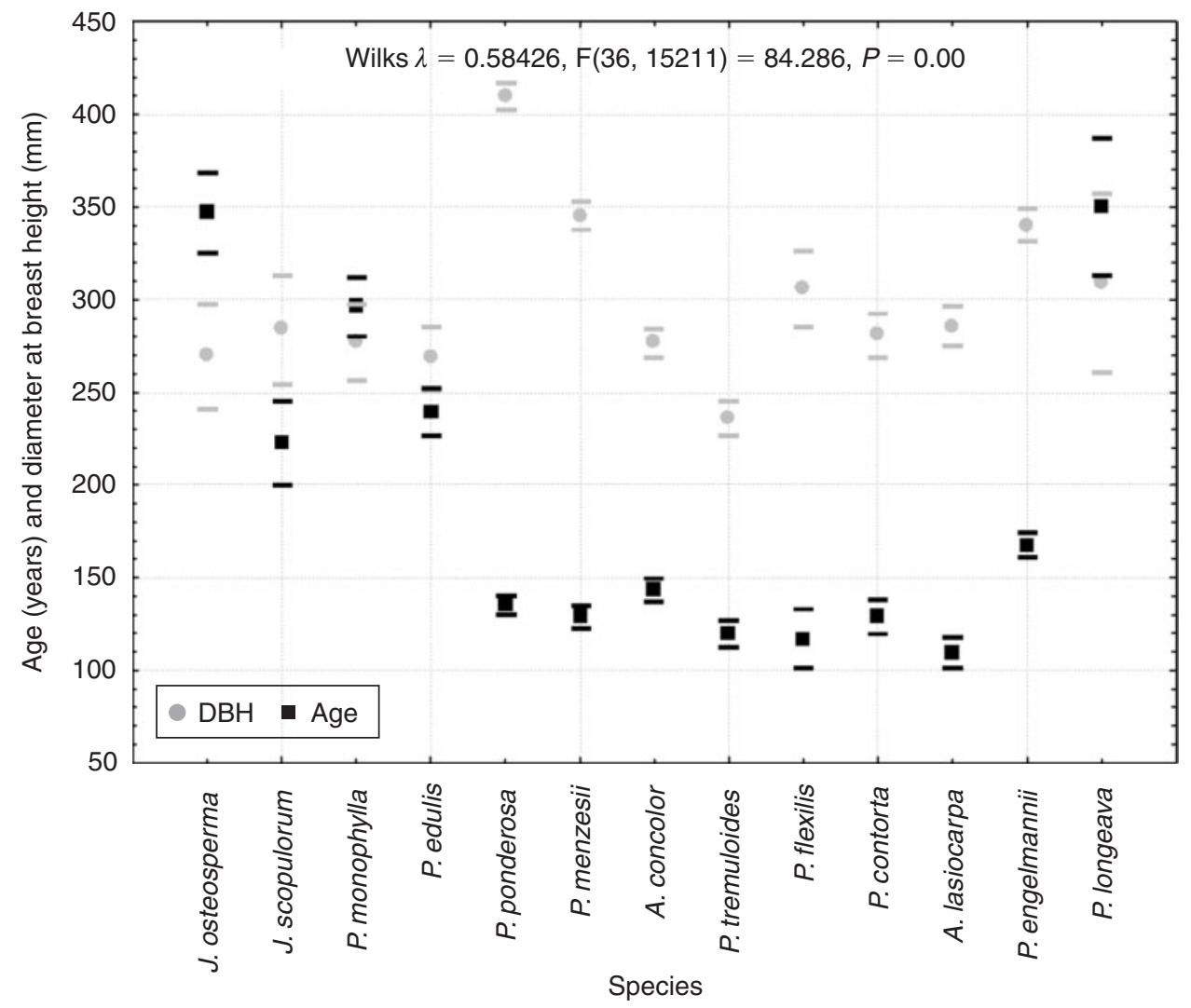

Fig. 5. ANOVA of age and diameter at breast height (DBH) by species and site. Horizontal bars represent $95 \%$ confidence intervals. 


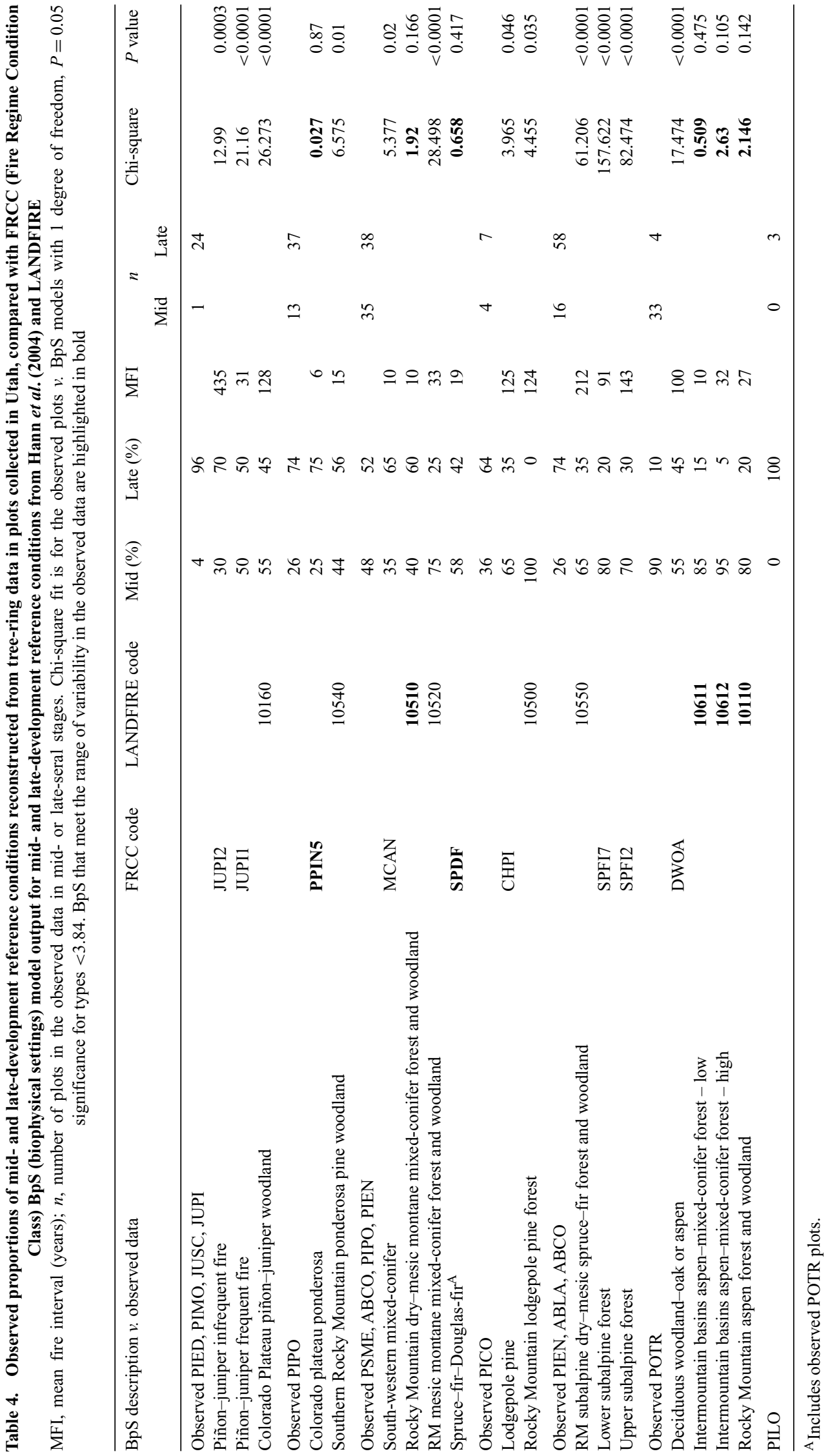



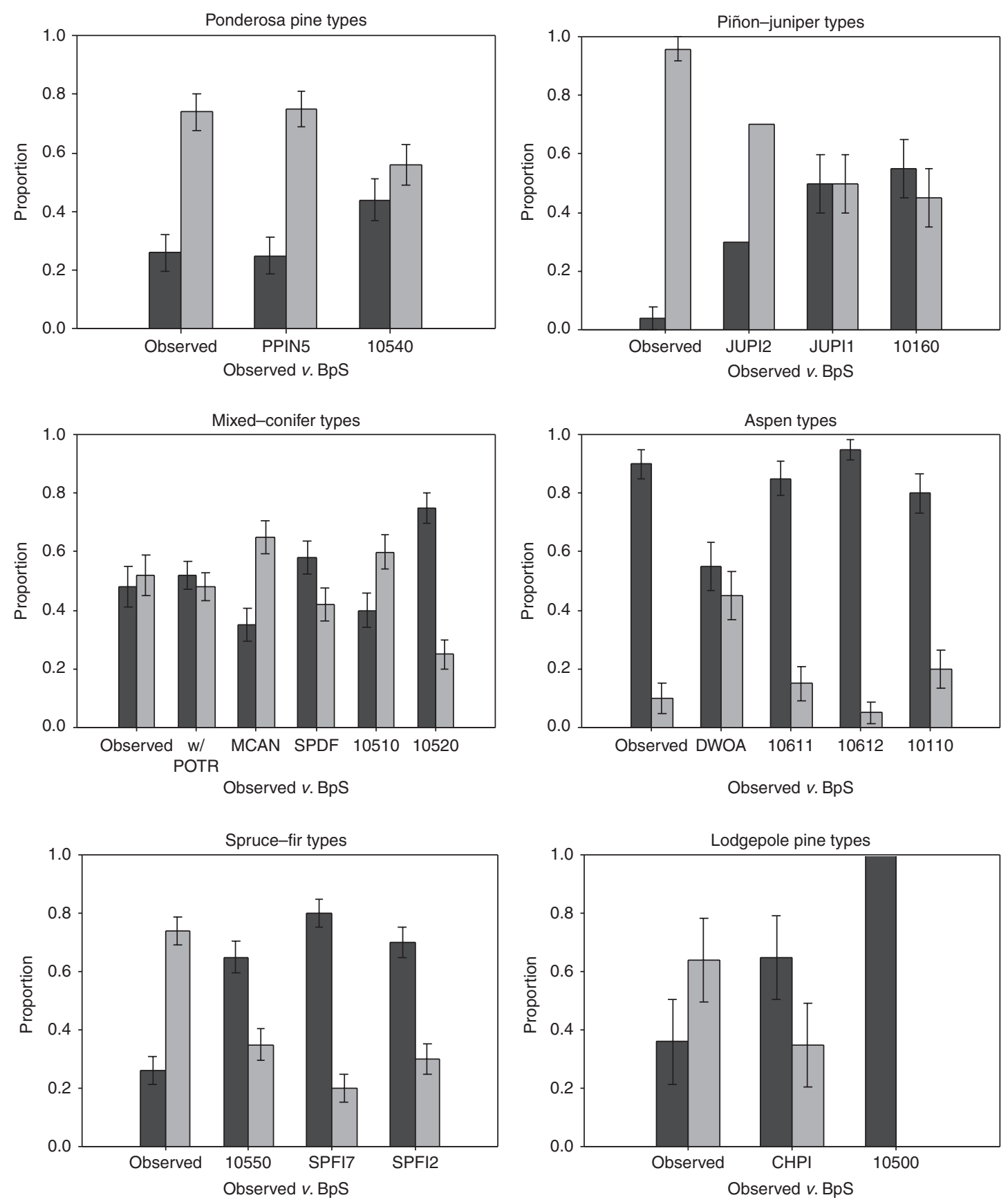

Fig. 6. Proportion of plots observed in the tree-ring data compared to FRCC (Fire Regime Condition Class) and LANDFIRE modeled reference condition proportions. Error bars were generated by calculating the $95 \%$ confidence interval from sample variance and standard error of observed points. Tree-ring results are on the left (e.g. observed), FRCC and LANDFIRE models are listed by their four-letter abbreviations on the right (e.g. PPIN5, 10540, etc.).

age-diameter relationships for determining reference condition proportions. Variations in age-size relationships both within species and among sites (Figs 2-5) may limit the ability to accurately gauge departure from estimated historical composition based on VDDT model results. Generally poor relationships between size and age may result in misassignment of current reference condition proportions based only on visual estimates, which may in turn lead to misassignment of the FRCC index.

Better correspondence between the tree-ring data and some BpS models indicates that VDDT models more accurately reflect historical forest structure in frequent-fire forest types such as ponderosa pine, mixed-conifer and aspen, than in 
Table 5. LANDFIRE accuracy by BpS (biophysical settings) and EVT (existing vegetation type)

Code is the LANDFIRE map code for BpS or EVT type, $n$ is number of plots tested, and \% is percentage that were accurately mapped based on tree-ring data at plot scale

\begin{tabular}{|c|c|c|c|}
\hline & Code & $n$ & $\%$ \\
\hline \multicolumn{4}{|l|}{ BpS } \\
\hline Rocky Mountain aspen forest and woodland & 10110 & 31 & 32 \\
\hline Rocky Mountain lodgepole pine forest & 10500 & 7 & 43 \\
\hline Rocky Mountain dry-mesic montane mixed-conifer forest and woodland & 10510 & 6 & 33 \\
\hline Rocky Mountain mesic montane mixed-conifer forest and woodland & 10520 & 11 & 64 \\
\hline Southern Rocky Mountain ponderosa pine woodland & 10540 & 19 & 53 \\
\hline Rocky Mountain subalpine dry-mesic spruce-fir forest and woodland & 10550 & 82 & 66 \\
\hline Intermountain basins aspen-mixed-conifer forest - low elevation & 10611 & 22 & 82 \\
\hline Intermountain basins aspen-mixed-conifer forest - high elevation & 10612 & 31 & 77 \\
\hline Intermountain basins mountain mahogany woodland and shrubland & 10620 & 6 & 50 \\
\hline \multicolumn{4}{|l|}{ EVT } \\
\hline Rocky Mountain aspen forest and woodland & 2011 & 26 & 50 \\
\hline Colorado Plateau piñon-juniper woodland and shrubland & 2016 & 43 & 37 \\
\hline Rocky Mountain lodgepole pine forest & 2050 & 19 & 63 \\
\hline Southern Rocky Mountain ponderosa pine woodland & 2054 & 24 & 46 \\
\hline Rocky Mountain subalpine dry-mesic spruce-fir forest and woodland & 2055 & 53 & 79 \\
\hline Intermountain basins aspen-mixed-conifer forest and woodland & 2061 & 64 & 67 \\
\hline Abies concolor forest alliance & 2208 & 14 & 71 \\
\hline
\end{tabular}

infrequent-fire types such as spruce-fir and piñon-juniper (Fig. 6). BpS reference condition models were determined by managers and scientists familiar with the local ecology of each region during regional workshops. BpS types that are considered to be representative of each region were identified and described based on available historical and ecological data. Some BpS types, such as ponderosa pine and dry mixed-conifer forests, have extensive fire and forest history data with which to parameterize VDDT model runs. Other BpS types are less well studied and their fire and vegetation histories less certain, especially across the range of environmental and community variation within and between regions. The better correspondence between modeled and reconstructed reference conditions in frequent-firetype models (ponderosa pine and mixed-conifer forest types; Fig. 6) is likely related to the greater amount of fire and forest history research that has been conducted in these forest types. Conversely, fire-infrequent types (spruce, and piñon-juniper woodland types; Fig. 6) have had less fire history research conducted, with the result that their fire regimes and successional patterns are less well documented for input to VDDT modeling. Furthermore, infrequent-fire types generally have fewer observations of historical fires and forest successional changes available for adequate characterization of fire regime parameters for VDDT modeling (e.g. Brown et al. 2008a).

Another factor that undoubtedly results in varying model and data results is that individual-site fire histories often have experienced contingent historical events that lead to differences from a 'typical' or average fire regime of a particular forest type. Stochastic modeling in FRCC and LANDFIRE generalizes vegetation and its fire regimes into generic types and does not take into account site-specific variability or, more importantly, the history of climate variations or other disturbances that may have affected changes in community structure through time. Variations in site histories undoubtedly contribute to variations in ratios of actual from modeled reference conditions. For example, spruce-fir and lodgepole pine FRCC and LANDFIRE BpS models predict more mid- than latedevelopment stands, but the Utah tree-ring data found the opposite (Fig. 6). This may be due to longer fire intervals in this region than in other areas, leading to generally older stands across landscapes. Many spruce trees found in the tree-ring study were $>300$ years old at the time of sampling and probably resulted from fires that occurred in the late $1600 \mathrm{~s}$, most commonly in 1685 (Heyerdahl et al. 2005). However, the current presence of older rather than younger stands does not mean that these forests are outside their historical ranges of variability in either their fire regime or forest structure, but rather that they have not had extensive fires in the intervening period that would have resulted in a larger proportion of mid-successional stands as suggested should be present based on VDDT model results. Without taking into account this history of the forest landscapes, the VDDT models suggest that there is current departure in the landscape proportions of reference conditions in Utah spruce-fir and lodgepole pine forests.

Taking into account differences in fire histories, the trend of model results toward older or younger successional classes in each BpS may be more important to consider in FRCC assessments rather than the absolute proportions of stand structures. This may provide a more realistic perspective for assessing whether a particular BpS should be considered as inside or outside of its historical range of variation. For example, the tree-ring fire data for piñon-juniper (P-J) woodlands show the majority of stands are currently in late-development structural stages (Fig. 6). The FRCC BpS model JUPI2 (Table 4) also predicts more late-development trees than younger, but underpredicts what was found in the tree-ring data. The sensitivity of the VDDT model to fire frequency is critical to the setting of reference conditions. The model inaccuracy may be due to the model's fire 
return interval, currently predicted to be $\sim 450$ years. If the interval is increased ( $\sim 1000$ years $)$, the model begins to more closely reflect the tree-ring results. A recent assessment of (P-J) ecosystems in the western US concluded that fire was only a minor disturbance in many less productive stands because of lack of both surface and crown fuels with which to carry fire (Romme et al. 2009). We believe that many of the Utah stands sampled probably fell into this category of fire regime historically, which means that if the longer intervals had been used in VDDT modeling, the reference conditions would likely be closer to what was found in the tree-ring data. The error may also be due to the definition of a mid-development stand in terms of the age; the mean ages of sampled piñon and juniper were among the highest in the tree-ring study. The mid-definition could be changed for P-J to an older age class by species to define the mid- from late-successional classes in the reference conditions.

Good correspondence between the tree-ring data and models for ponderosa pine (PPIN5), aspen (10110), and mixed-conifer (SPDF, 10510; Fig. 6) suggests that the reference conditions for these BpS were accurately modeled by VDDT parameters, at least in the Utah study sites. However, results of this study suggest that inaccuracy in piñon-juniper and subalpine types makes any decision based on a VDDT output possibly subject to error. For BpS types in which disturbance may not be the major or only factor in tree recruitment, VDDT models may need further evaluation. Additional empirical disturbance and forest history sampling in piñon-juniper, spruce-fir, and lodgepole pine types should increase the available information about these systems to use in VDDT modeling. However, because of generally longer fire intervals in these forests, any departure from historical to present conditions may be less than in frequent-fire $\mathrm{BpS}$ such as ponderosa pine and mixed-conifer forests. A possible result of inaccurate estimations of departure and wrong FRCC classification may be the application of incorrect management actions that could lead to even further departure from historical conditions (see also Romme et al. 2009).

The only accurate way to establish the age of a stand is to physically sample the trees for ages. We suggest based on the results of our comparison that at least some limited age sampling is needed for FRCC assessments. This sampling probably should include removing cores from the field and crossdating by trained dendrochronologists to most accurately characterize age and successional status of stands. Additional field-sampled fire history and stand establishment data, especially in the lesswell-studied ecosystems, should further increase the accuracy of VDDT models through better dynamic estimations of age structures and relationships with fire regimes. However, we also realize that this type of sampling is expensive and - perhaps more critically to the efficient use of FRCC in forest management decisions - more time-consuming than FRCC visual assessment methods as currently practiced. Nevertheless, we suggest that some sort of compromise solution could be found that would provide both the most accurate as well as timely data possible for FRCC assessment needs.

\section{LANDFIRE maps}

Zhu et al. (2006) used a cross-validation technique to determine that existing vegetation data layer accuracies are between
60 and $89 \%$ in LANDFIRE maps. Our study's comparison of LANDFIRE and tree-ring data falls on the lower end of the estimate of Zhu et al. (2006) (Table 4). When broken down by BpS and EVT, some types are more accurately represented in LANDFIRE data than others. EVT mapping in LANDFIRE is most accurate for the mixed-conifer and spruce-fir types. These forests generally have the densest and most continuous canopies, and may have been easiest to identify through remote sensing methods because of their continuous canopies and more distinctive NDVI reflectance in Landsat spectral bands (Zhu et al. 2006). Conversely, sparser canopy cover may have led to lower accuracy in other types such as piñon-juniper, which is similar to what Zhu et al. (2006) found. It should be noted, however, that piñon-juniper plots sampled for the tree-ring study were generally found in ecotonal areas near lower ends of study sites, and may not be wholly representative of piñon-juniper $\mathrm{BpS}$ as defined in the LANDFIRE mapping effort.

\section{Conclusion}

Historical forest conditions reconstructed from tree-ring data provide opportunities for comparison with FRCC and LANDFIRE modeled vegetation data across multiple forest types. The tree-ring reconstructions we examined suggest that reference conditions are better modeled in frequent-fire forest types but not necessarily in infrequent-fire forest types, at least in Utah forests. Additional studies in fire-infrequent forest types should increase understanding of historical stand compositions, fire histories, and other disturbances with which to better parameterize VDDT reference condition models. The greatest amount of fire history research has been conducted in ponderosa pine and mixed-conifer forests, which likely contributed to the better correspondence between tree-ring data and VDDT model results that we found in this study. We consider this study as only a first step in comparison of empirical vegetation data with vegetation models used in both FRCC assessments and the nationwide LANDFIRE mapping effort. Tree-ring data provide an opportunity to compare site-specific vegetation patterns and fire regime variations that are often not easily accounted for in modeling efforts. Revised methods for assessing FRCC may need to take into greater account both tree ages and stand histories to more accurately compare with model results. We also suggest that ranges of reference conditions be incorporated into the $\mathrm{BpS}$ classifications to better take into account fire and forest histories rather than trying to establish average conditions that must be met for a FRCC index to be assigned.

\section{Acknowledgements}

We are especially grateful to Emily Heyerdahl, Stan Kitchen, and Marc Weber for sharing data from the tree-ring project in Utah. The Utah project was funded by the Joint Fire Science Program, Fishlake National Forest, Rocky Mountain Research Station, Utah Bureau of Land Management, and Rocky Mountain Tree-Ring Research. We thank Brendan Ward, Kathy Schon, and Jim Menakis with the LANDFIRE project for sharing their expertise and data for this research. Phil Guertin, Steve Yool, Tom Swetnam, Wendel Hann, Steve Barrett, and three anonymous reviewers provided valuable comments on the manuscript. This research was funded by the National Interagency Fuels Technology Transfer Team that is responsible for development and updating of FRCC methods and vegetation models. 


\section{References}

Beukema SJ, Kurz WA (2003) 'Vegetation Dynamics Development Tool and User's Guide, Version 4.0.' (ESSA Technologies Ltd: Vancouver, BC)

Brown PM (2006) Climate effects on fire regimes and tree recruitment in Black Hills ponderosa pine forests. Ecology 87, 2500-2510. doi:10.1890/0012-9658(2006)87[2500:CEOFRA]2.0.CO;2

Brown PM, Cook B (2006) Early settlement forest structure in Black Hills ponderosa pine forests. Forest Ecology and Management 223, 284-290. doi:10.1016/J.FORECO.2005.11.008

Brown PM, Schoettle AW (2008) Fire and stand history in two limber pine (Pinus flexilis) and Rocky Mountain bristlecone pine (Pinus aristata) stands in Colorado. International Journal of Wildland Fire 17, 339-347. doi:10.1071/WF06159

Brown PM, Wu R (2005) Climate and disturbance forcing of episodic tree recruitment in a south-western ponderosa pine landscape. Ecology $\mathbf{8 6}$ 3030-3038. doi:10.1890/05-0034

Brown PM, Heyerdahl EK, Kitchen SG, Weber MH (2008a) Climate effects on historical fires in Utah. International Journal of Wildland Fire 17 28-39. doi:10.1071/WF07023

Brown PM, Wienk CL, Symstad AJ (2008b) Fire and forest history at Moun Rushmore. Ecological Applications 18, 1984-1999. doi:10.1890/071337.1

Comers P, Faber-Langendoen D, Evans R, Gawler S, Josse C, Kittel G, Menard S, Pyne M, Reid M, Schulz K, Snow K, Teague J (2003) 'Ecological Systems of the United States: a Working Classification of US Terrestrial Systems.' (NatureServe: Arlington, VA)

Hann WJ, Bunnell DL (2001) Fire and land management planning and implementation across multiple scales. International Journal of Wildland Fire 10, 389-403. doi:10.1071/WF01037

Hann WJ, Strohm DJ (2003) Fire regime condition class and associated data for fire and fuels planning: methods and applications. In 'Fire, Fuel Treatments, and Ecological Restoration: Conference proceedings', 16-18 April 2002, Fort Collins, CO. (Tech. Eds PN Omi, LA Joyce) USDA Forest Service, Rocky Mountain Research Station, Proceedings RMRS-P-29, pp. 337-443. (Fort Collins, CO)

Hann WJ, Havlina D, Shlisky A, Barrett S, Pohl K (2003) Project scale Fire Regime and Condition Class guidebook. (USDA Forest Service, US Department of the Interior, The Nature Conservancy, and Systems for Environmental Management) Available at http://www.frcc.gov/ [Verified 12 September 2008]

Hann W, Shlisky A, Havlina D, Schon K, Barrett S, DeMeo T, Pohl K, Menakis J, Hamilton D, Jones J, Levesque M (2004) Interagency Fire Regime Condition Class Guidebook. USDA Forest Service, USDI, The Nature Conservancy, and Systems for Environmental Management Available at http://www.frcc.gov/ [Verified 12 September 2008]

Heyerdahl EK, Brown PM, Kitchen S, Weber MH (2005) Historical fire regimes and forest structure in Utah forests. Final report to the Utah State Bureau of Land Management. Available at http://www.rmtrr.org/ Utahfirehistory/ [Verified 12 September 2008]

Heyerdahl EK, Miller RF, Parsons RA (2006) History of fire and Douglasfir establishment in a savanna and sagebrush-grassland mosaic, southwestern Montana, USA. Forest Ecology and Management 230, 107-118. doi:10.1016/J.FORECO.2006.04.024
HFRA (2003) Healthy Forest Restoration Act of 2003. Public Law 108-148, Statutes at Large 117:1887.

Jonsson B, Holm S, Kallur H (1992) A forest inventory method based on density-adapted circular plot size. Scandinavian Journal of Forest Research 7, 405-421. doi:10.1080/02827589209382733

Keane RE, Rollins MG, McNicoll CH, Parsons RA (2002) Integrating ecosystem sampling, gradient modeling, remote sensing, and ecosystem simulation to create spatially explicit landscape inventories. USDA Forest Service, Rocky Mountain Research Station, General Technical Report RMRS-GTR-92. (Fort Collins, CO)

Küchler AW (1964) Potential natural vegetation of the conterminous United States. American Geographical Society, Special Publication 36.

Morgan P, Hardy CC, Swetnam TW, Rollins MG, Long DG (2001) Mapping fire regimes across time and space: understanding coarse and finescale fire patterns. International Journal of Wildland Fire 10, 329-342. doi:10.1071/WF01032

NRCS (2003) 'National Range and Pasture Handbook.' (USDA National Resource Conservation Service: Washington, DC)

Rollins MG, Frame CK (2006) The LANDFIRE Prototype Project: nationally consistent and locally relevant geospatial data for wildland fire management. USDA Forest Service, Rocky Mountain Research Station, General Technical Report RMRS-GTR-175. (Fort Collins, CO)

Romme W, Allen C, Bailey J, Baker W, Bestelmeyer B, Brown P, Eisenhart K, Floyd L, Huffman D, Jacobs B, Miller R, Muldavin E, Swetnam T, Tausch R, Weisberg P (2009) Historical and modern disturbance regimes, stand structures, and landscape dynamics in piñon-juniper vegetation of the western United States. Rangeland Ecology and Management 62 , 203-222. doi:10.2111/08-188R1.1

Schmidt KM, Menakis JP, Hardy CC, Hann WJ, Bunnell DL (2002) Development of coarse-scale spatial data for wildland fire and fuel management USDA Forest Service, Rocky Mountain Research Station, General Technical Report RMRS-GTR-87. (Fort Collins, CO)

Schoennagel T, Veblen TT, Romme WH (2004) The interaction of fire, fuels, and climate across Rocky Mountain forests. Bioscience 54, 661-676. doi:10.1641/0006-3568(2004)054[0661:TIOFFA]2.0.CO;2

Shlisky A, Hann WJ (2003) Rapid scientific assessment of mid-scale fire regime conditions in the Western US. In 'Proceedings, 3rd International Wildland Fire Conference', 3-6 October 2003, Sydney, Australia.

StatSoft Inc. (2008) Statistica (data analysis software system), version 8.0. Available at www.statsoft.com [Verified 12 September 2008]

USDA/USDI (2000) National fire plan: managing the impact of wildfires on communities and the environment. A report to the President in response to the wildfires of 2000. Available at http://www.fireplan.gov/ [Verified 12 September 2008]

Zhu Z, Vogelmann J, Ohlen D, Kost J, Chen X, Tolk B (2006) Mapping existing vegetation composition and structure for the LANDFIRE Prototype Project. In 'The LANDFIRE Prototype Project: Nationally Consistent and Locally Relevant Geospatial Data for Wildland Fire Management'. (Tech. Eds MG Rollins, CK Frame) USDA Forest Service, Rocky Mountain Research Station, General Technical Report RMRS-GTR-175. (Fort Collins, $\mathrm{CO}$ )

Manuscript received 3 January 2008, accepted 3 June 2009 